\title{
Impact of the Digital Factory on the Production Planning Process
}

\author{
Eberhard Haller, Emmerich F. Schiller and Ingo Hartel \\ DaimlerChrysler AG, Mercedes Car Group, D-71059 Sindelfingen, Germany. \\ Email:emmerich.schiller@daimlerchrysler.com
}

\begin{abstract}
Changing conditions in the automotive industry mean that assembly lines have to be built faster and at an increasingly early stage of the product development process. Since the required efficiency improvements could not be achieved with conventional planning processes, organisational structures and software systems, DaimlerChrysler AG introduced the Digital Factory strategic project in mid-2000. At the centre of this project is the complete and integrated digitisation of all areas of production planning. The following article describes the digitisation process - from the selection and introduction of suitable software and IT infrastructure, through the development of methods for efficient planning, to the changing and restructuring of the production planning process and the organisation.
\end{abstract}

Key words: Digital factory, Production planning process, Digital production planning

\section{CHANGING CONDITIONS IN THE AUTOMOTIVE INDUSTRY}

In order to maintain and enhance its leading position in an increasingly competitive market, DaimlerChrysler AG launched a wide-ranging model offensive several years ago (SCHILLER et al. 2003). In addition to developing new variants of existing models and vehicle types, a key component of this strategy was the introduction of entirely new vehicle concepts. Alongside this model offensive, DaimlerChrysler initiated a range of measures to significantly reduce product development times. For example, the introduction of CAD systems and the associated shift to computer-aided 3D model- 
ling led to a noticeable shortening in the time needed for the design process. The introduction of a company-wide PDM system also simplified and therefore accelerated the product data acquisition and management processes (in particular those applicable to design data). But the changes went further than simply introducing and implementing new IT systems; the processes and workflows in product development were also restructured - especially those relating to product design.

A few years ago it became apparent that those technical and organisational changes needed to be matched by adjustments within the planning departments that take the designed vehicles and put them into production. Shorter development times, for example, mean that the associated assembly lines have to be planned faster and earlier. Production planning was therefore faced with the challenge of significantly improving the efficiency of its operations in order to keep pace with product development. There are two critical factors to this: Firstly, assembly lines will in future have to be both planned and tooled for an increasing range of vehicle models. Secondly, the introduction of new, innovative vehicles often demands the implementation of new production methods and processes, which must first be made ready for standard production by production planning.

As well as improving the efficiency of existing planning processes, production costs also need to be shaved. In addition to the continuous (in the sense of CIP) drive to reduce these costs, significant potential has to be realised with every type change in a vehicle programme. This is the only way for production at existing sites to remain profitable and competitive in the long term. In order to achieve real cost savings, production needs must be considered early on in the product development process. Much more so than in the past, production planning therefore has be involved in the product in a DFMA (Design for Manufacture and Assembly) sense from the early stages. It is well known that the cost of making changes in the later stages is disproportionately high. Volume production conditions can only be taken into account in the early phases of product design, however, if design engineers and planners work closely together in a concurrent engineering approach (HALLER, SCHILLER 2003). The aim of this type of co-operation is to achieve a win-win situation for both design engineering and planning, in other words shorter product development and production planning times combined with improved planning quality and greater maturity of product and production process.

In order to successfully implement concurrent engineering, communication and co-operation between the departments concerned are essential. However, this requires both design engineers and production planners to be operating on an equal footing in terms of both technology and processes. As far as the introduction and use of IT systems is concerned, the intensive digitisation process undertaken in design engineering over recent years has put 
it a good way ahead of production planning. Figure 1 shows how significant progress has been made in establishing digital methods in design engineering, whereas digitisation in conventional production planning is far less advanced. Here two-dimensional, alphanumeric planning supplemented by a number of individual simulation tools, such as material flow simulation, still dominates.

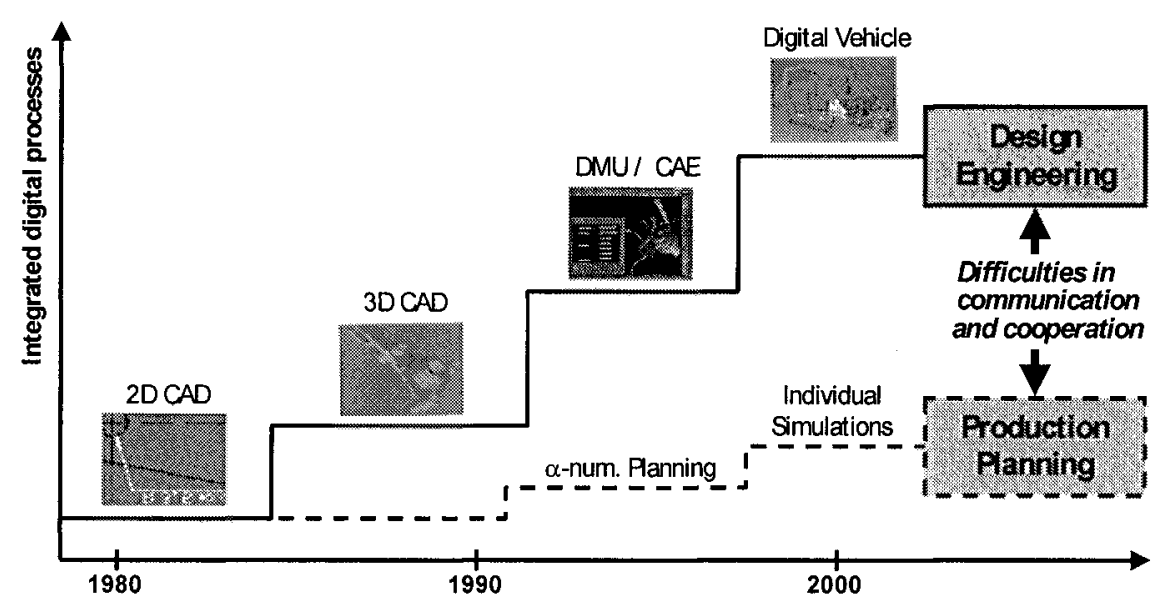

Figure 1. Digitisation in design engineering and production planning

In order to close this technology gap between design engineering and production planning, DaimlerChrysler AG launched the Digital Factory (DiFa) strategic project in mid-2003 (SCHILLER, SEUFERT 2003). The aim of this project is to digitise production planning in a way that is comparable to the introduction of $\mathrm{CAD}$ in design engineering.

\section{DIGITISATION OF PRODUCTION PLANNING}

A prerequisite for the digitisation of production planning was the choice of suitable software and the IT infrastructure needed to run it. As well as including the actual planning functions such as process modelling, planning validation, analysis/reporting and controlling, the software also had to allow the integration of data and applications between design engineering, process planning (e.g. for body-in-white or assembly) and plant planning (e.g. of the building or equipment). In data integration in particular, direct access by the planning departments to product geometry data and parts lists produced by design engineering is critical. The digitisation of production planning at DaimlerChrysler began at a good time since it coincided with a move by 
software companies that had previously developed CAD systems to start expanding and integrating planning functions into their existing systems.

On the IT infrastructure side, standard technology has been used systematically right from the start. In other words, the digital planning software has to run on conventional PCs with upgraded memory and graphics processing and display capabilities. This is the only way of ensuring that it can subsequently be distributed to several hundred employees. As well as providing production planners with digital planning capability at their workstations, a "power wall" has been set up at Mercedes-Benz' central production planning and design engineering facility in Sindelfingen specifically for the visualisation of major planning issues such as entire lines or plant halls. The $13 \mathrm{~m}^{2}$ projection screen can be used to display large-scale production areas 1:1 and to show moving 3D simulations of production processes.

The digital planning software and IT infrastructure provided by the Digital Factory form the basic building block for integrated, digital cooperation between production planning and design engineering. Giving planners access to digital product data directly within the planning environment enables them to check the data against production requirements far more easily and thoroughly than before. Using three-dimensional digital models, planners can work out their requirements and suggested modifications - particularly regarding production-oriented product design under standard production conditions - at a very much earlier stage and on a much sounder basis than before (SCHILLER, SEUFERT 2004). In addition to the actual software and IT infrastructure, however, this approach also requires the provision of appropriate methods for efficient planning. Figure 2 shows that alongside intensive measures to standardise production resources and processes, such methods must include detailed definitions of workflows which set out the operational planning steps, including roles and responsibilities.

The following account demonstrates how these prerequisites were established in the Digital Factory using as an example the testing of welding guns as part of the planning process for body-in-white production. This test involves checking the geometrical accessibility for welding guns of all weld points on a vehicle. In conventional planning this used to be done using real welding guns on the first prototype vehicles to be assembled, but in the Digital Factory the test can be carried out on the digital vehicle. Data integration allows the planner to access not only the geometrical data for the product, but also the relevant weld point information (e.g. position and alignment of the weld point, associated components, weld point diameter). The functions included in the planning software allow the planner to check the weld points after entering predefined parameters. This simulation can be performed either manually or automatically and is based on the manufacturing processes (joining sequences) defined by the planner and displayed in the 
system. The welding guns used in the digital test come from an approved standard catalogue used by the Mercedes Car Group. The result of the test is a list from which the planner can determine which weld points are accessible with the selected standard guns and which are not, along with the minimum number of guns that are required. To ensure that in future this type of test is no longer restricted to specialist operators, a detailed workflow with clearly defined roles has been developed. In addition, production planners have received training in the steps involved so that simulation experts now rarely need to be called in.

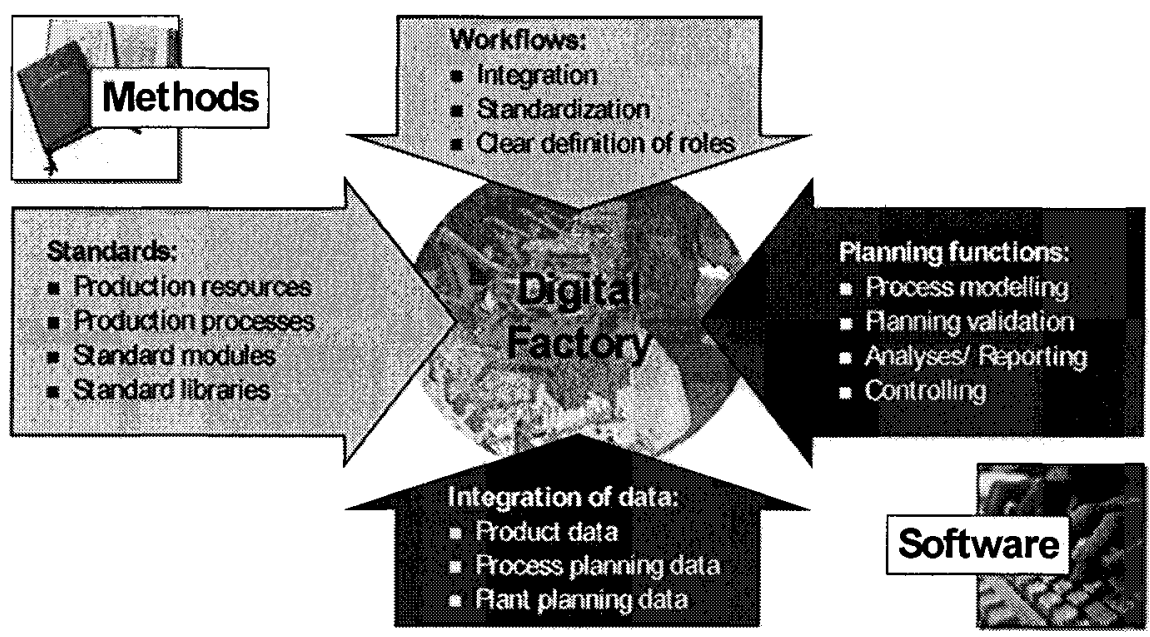

Figure 2. Prerequisites for the Digital Factory

The welding gun test and other methods developed in various vehicle projects that are currently in the development and planning phase have since been successfully used at an operational level. In order to achieve this, not only the software and methodology requirements outlined above had to be fulfilled but also the existing processes and organisational structures that were based on conventional planning had to be adapted for digital production planning. Thereby the new production planning process described below was developed and introduced as part of a comprehensive restructuring initiative

\section{NEW PRODUCTION PLANNING PROCESS}

The starting point for the design of the new planning process was the need arising from the changed conditions for a stronger product input from 
planning in the early stages of vehicle development. In line with the development process, which comprises a concept phase and a vehicle development phase, the new planning process is divided into a standard planning phase and a real planning phase (see Figure 3).

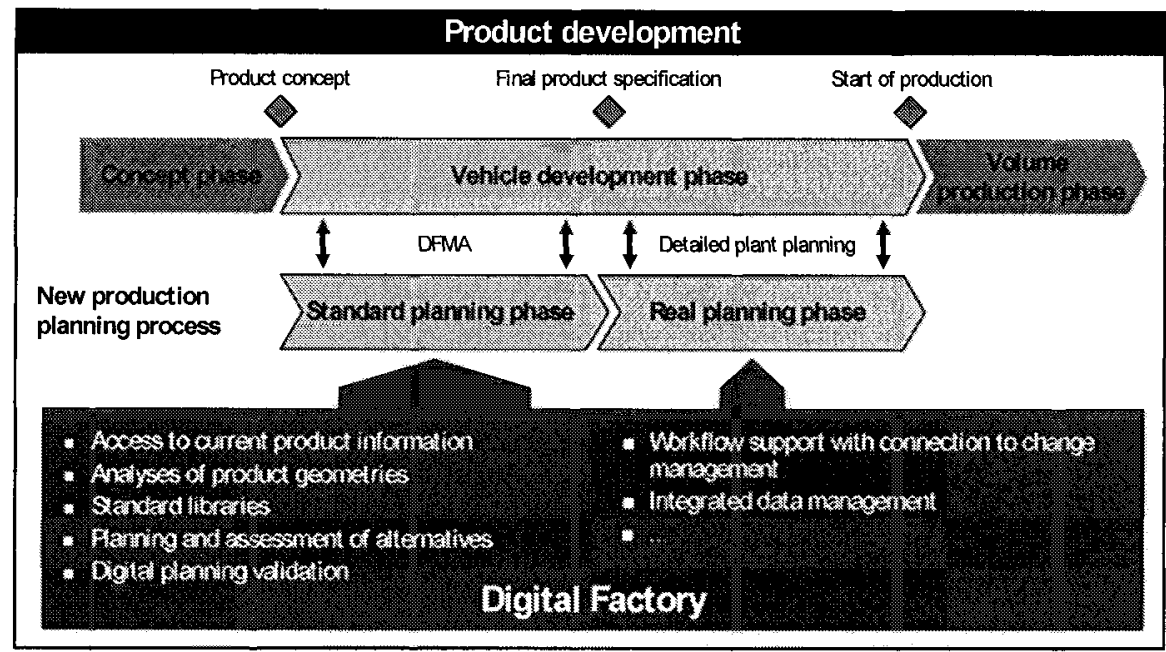

Figure 3. New production planning process

\subsection{Standard Planning Phase}

The emphasis during the standard planning phase is on working on the product - in other words production-oriented product design. Defined product statuses that exist at specific milestones (quality gates) in vehicle development are tested here under standard production conditions, using the latest product and 3D geometry data for defined vehicle configurations. This data can then be used as a basis for the start of digital planning for a vehicle programme. Suggested improvements and tentative solutions worked out by the planners during this phase can then be discussed with the design engineers on an ongoing basis.

The standard planning phase begins with the specification of the product concept around five years before the start of volume production. The end of the standard planning phase roughly coincides with the creation of the final product specification by design engineering. During this period the production planning activities are broken down into areas such as digital body-inwhite, assembly, logistics/equipment and plant planning. Production issues in the various planning areas are taken into consideration using standard modules. By using individual elements from a range of standard libraries, 
alternative production lines (for body-in-white for example) can be very quickly constructed, analysed and modified if necessary, and also costed out and compared with one another. The results from the digital planning validation in particular are taken into consideration here. In the standard planning phase, the digital planning validation is responsible for the conceptual testing of the vehicle's production feasibility. For body-in-white production, this includes checking the geometric accessibility of the various weld points and the manufacturing sequence and concept or layout. Similarly, in assembly planning the digital planning validation provides results about the safe and ergonomic assembly of components under standard production conditions, and about assembly sequences at stations and on production lines.

\subsection{Real Planning Phase}

In the real planning phase the valid planning status from the standard planning phase is then transferred to a real, specific plant situation. The starting point for this phase is the "design freeze" which occurs when the final product specification for the entire vehicle is agreed. This gives the product and production concept a much greater stability than it has in the standard planning phase. In the real planning phase the production systems are planned in increasing detail as time goes on, taking account of physical conditions at the production site (e.g. existing buildings), technical conditions (e.g. degree of automation) and specified planning parameters (e.g. number of vehicles to be produced).

\subsection{Benefits of the New Production Planning Process}

This new planning process, with the Digital Factory as an essential element, enables production planners to find optimal solutions at a very early stage using digital data. This has been confirmed in a number of vehicle programme projects since the introduction of the new process. Furthermore, empirical evidence gathered over the course of these projects shows that the new production planning process offers real benefits in the following areas in particular:

- Increased planning efficiency and planning speed through the use of standard libraries, data integration and automation. Improvements of over $20 \%$ are achievable here.

- Improved quality of planning results through systematic digital testing and plausibility checks. This can be seen in line capacity utilisation, for example, which has been increased by 10 to $15 \%$ with the help of the Digital Factory. 
- Improved processes of agreement between engineering, planning and production through integrated workflows, the ability to test alternatives and the visualisation of planning results. This has allowed optimisation discussions between design engineers and planners to be conducted on a much sounder footing, leading directly to a marked reduction in subsequent design changes.

This combination of benefits has brought about the required increase in the maturity of product and production process. The key factor here is the flow of requirements and findings from planning and production into the product development process. Problems can be identified far earlier than before and resolved jointly with appropriate measures. The digital planning validation is a particularly good example of this. With the new production planning process the joining and assembly sequences are also tested under standard production conditions using DMU. Previously this had to wait until the first real assembly of the vehicle in the zero series at the end of the vehicle development phase. The Digital Factory with the digital planning validation mean that any necessary changes can be made roughly 17 months earlier. Analyses comparing conventionally planned vehicle models that are still in production with new vehicle models that were planned and tested with the aid of the Digital Factory show that approximately $30 \%$ of the problems that arise at the start of vehicle volume production can be avoided.

\section{IMPACT OF THE DIGITAL FACTORY ON ORGANISATION AND CO-OPERATION BETWEEN DESIGN ENGINEERING AND PRODUCTION PLANNING}

Early vehicle projects clearly showed the benefits of the Digital Factory through specific examples. Now the potential arising from the groundwork done in terms of software and methods and the new production planning process has to be realised across the board for future vehicle models. If the Digital Factory is to be established on a sustainable footing, a far-reaching and comprehensive process of change is required. The new production planning process and the potential offered by digital planning software will only bring lasting benefits if the organisation is also adapted accordingly or restructured where necessary. The first organisational changes to have been implemented with the aim of establishing the Digital Factory on a broad basis are shown in Figure 4. We will then consider two specific examples: 


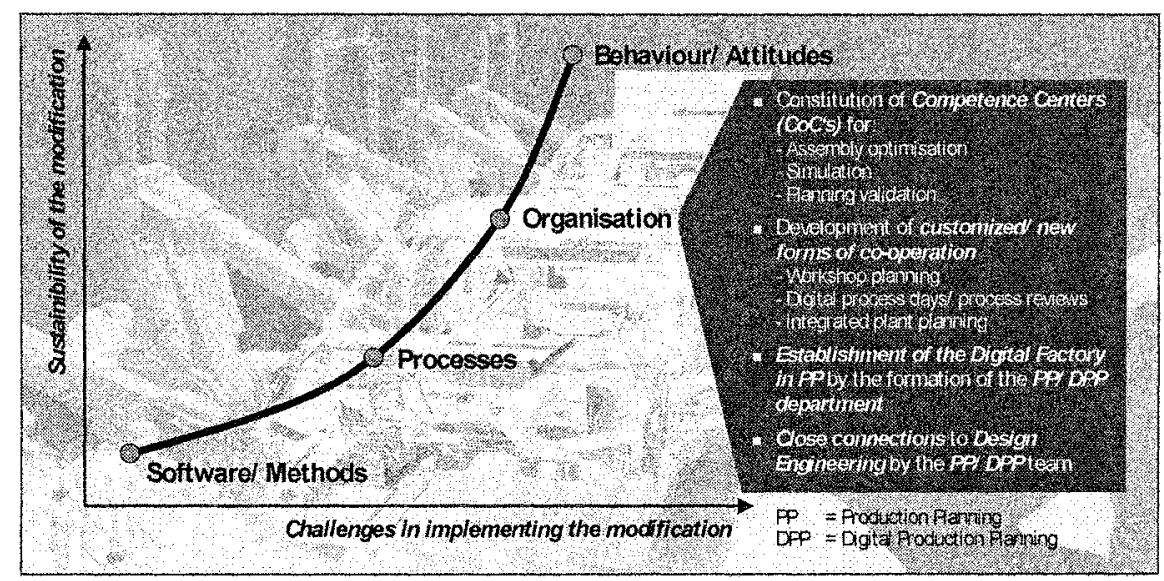

Figure 4. Organisational changes for the purposes of establishing the Digital Factory

- Competence centre for assembly optimisation: The Digital Factory offers expert tools for optimising assembly processes. To enable these to be used more widely, a special competence centre for assembly optimisation has been established. The centre comes under the production planning umbrella in the Mercedes Car Group. Its principal task is the planning, control and in some cases delivery of interdisciplinary workshops on the optimisation of assembly processes, e.g. balancing lines and stations. This has involved looking not only at vehicle programmes that are currently in the development and planning stage, but also at those that are in production today. Experts from assembly and logistics planning usually take part in the workshops. As they work together to develop and assess alternatives and find optimal overall solutions, staff from the competence centre offer help in the use of the various planning and testing tools from the Digital Factory. This procedure has increased capacity utilisation in the assembly process by up to 10 percent.

- Digital process days and process reviews. The purpose of digital process days is to visualise production planning statuses digitally, allowing them to be tested at an early stage. Whereas the competence centre provides continuous support for assembly planning, digital process days are oneoff events. They are planned according to the progress of vehicle projects. In advance of each digital process day the necessary test parameters and scenarios are decided. The individual tests are then performed with the planning software using the latest product data. On the process day itself, the detailed results of the tests are then presented to representatives from design engineering and production planning with responsibility for 
the vehicle projects. The current planning status is discussed within the group and assessed on the basis of checklists. Measures are devised to resolve any problems, in the form of design changes or process adjustments, for example. At the end of a digital process day the measures that have been devised are presented in a special management session to decision-makers from design engineering, production planning and production. In this way individual measures can be agreed immediately, and people nominated to ensure that they are carried out. In between digital process days there is also a mechanism for holding digital process reviews if required, where partial results from the digital planning validation can be presented to a smaller selected group of people, and preliminary measures decided upon together.

The organisational changes described here represent a major first step towards establishing the Digital Factory within DaimlerChrysler AG. Further steps are still needed, however. If the Digital Factory and Digital Production Planning (DPP) are to be established for the long term, a change in the behaviour and attitude of everyone concerned, at every level of the organisation, will also be required (see Figure 4).

To this end, a number of targeted activities have been undertaken since the start of the project. One of the most important of these involves training staff to use the Digital Factory. This begins with process training courses, where staff learn about the new processes, methods and procedures and about the changes they mean to the way they work. Only when planners have learnt about the new processes (workflows) and their consequences do they move on to systems courses on the use of the digital planning software.

Their subsequent hands-on work with the planning software is accompanied by psychology oriented work analyses. Interviews and activity logs are used to measure improvements in planning quality and the impact of the Digital Factory on planning contents and their time spread in comparison to conventional planning (SIMON, SCHILLER, HACKER 2004). Design recommendations for further developments to the methods and software in the Digital Factory are then derived from these results.

A new co-operation model, in which pilot users from the various departments work with staff from the Digital Factory project on current planning issues, has proven to be another useful way of broadening acceptance of the Digital Factory. Responsibility for the technical planning result still lies with the department, however. This new way of working has proven to be particularly popular with planners. 


\section{NEXT STEPS}

After more than three years, it is clear that the Digital Factory project represents a major step along the road towards true concurrent engineering. With the introduction of digital planning software and the implementation of methods for digital planning and validation production planning have now made comparable progress towards universal digitisation like design engineering. Through the digitisation of production planning, the new planning process and the organisational changes that have been made, design engineers and planners are now able to work together and communicate "eye-toeye" and with far less friction. This improved co-operation between design engineers and planners means that they can work together to realise their full joint potential. In future, production systems will not be planned, built or run until the product, the production processes and the production facilities have been digitally tested on the computer (SCHILLER, SEUFERT 2003). In contrast to conventional production planning, not only can solutions be reliably evaluated at a much earlier stage but alternative planning scenarios can also be developed quickly and at little cost. In this way, the Digital Factory enables the most promising alternative to be selected at a very early stage, thereby reducing the risk of subsequent changes and of wasted investment.

Despite - or possibly even because of - the advanced status of the Digital Factory at DaimlerChrysler, there are still things that remain to be done (HALLER, SCHILLER, SEUFERT 2003; HALLER 2003):

- In terms of software and methods, issues such as the integration of planning and layout data into existing EDM/PDM systems, integrating and managing large amounts of data, improving software performance, stability and user-friendliness, and extending the existing software planning functions and planning methods are paramount.

- In the area of processes, attention will be directed towards complexity management. To this end, roles, responsibilities, information flows and schedules need to be defined more precisely, and also described more clearly and simply.

- The changes to the organisation that have been made now need to be extended. More competence centres need to be built for specific areas, for example, and the new co-operation models must increasingly be made to apply across vehicle programmes. For example, as well as design engineers and planners, production staff (supervisors and operators) will increasingly take part in digital process days. In addition, organisational models allowing greater integration of suppliers into digital production planning need to be developed and implemented. 
- With regard to changing the behaviour and attitude of staff to the Digital Factory, the goal is to increase motivation through participation, which means that all staff concerned must now be included in training programmes and courses.

\section{REFERENCES}

\section{HALLER, E.:}

„Planungszeit um bis zu 40 Prozent verkürzen".

In: Automobil Industrie,

Würzburg, (2003)7-8, pp. 46-47.

HALLER, E.; SCHILLER, E. F.:

The Significance of Digital Manufacturing within the New Planning Process.

In: Human Aspects in Production Management.

Eds.: ZÜLCH, Gert; STOWASSER, Sascha; JAGDEV, Harinder S.

Aachen: Shaker Verlag, 2003, pp. 18-23.

(esim - European Series in Industrial Management, Volume 5)

HALLER, E.; SCHILLER, E. F.; SEUFERT, W.-P.:

Herausforderungen beim Hochlauf der Digitalen Fabrik.

In: Innovation in der Automobilproduktion und Produktionsplanung - Ausgewählte

Beiträge aus der industriellen Praxis.

Eds.: SCHILLER, E. F.; HALLER, E.

Aachen: Shaker Verlag, 2003, pp. 1-15.

SCHILLER, E.F.; ROLL, K.; WÖHLKE, G.; WIEGAND, K.:

Digital Manufacturing in Press Part Production.

In: Innovation in der Automobilproduktion und Produktionsplanung - Ausgewählte

Beiträge aus der industriellen Praxis.

Eds.: SCHILLER, E. F.; HALLER, E.

Aachen: Shaker Verlag, 2003, pp. 63-75.

SCHILLER, E. F.; SEUFERT, W.-P.:

Bis 2005 realisiert - Digitale Fabrik bei DaimlerChrysler.

In: Automobil Produktion,

Landsberg, 16(2002)2, pp. 20-30.

SCHILLER, E.F.; SEUFERT, W.-P.:

Virtual Automotive Production.

In: Business Briefing-Global Automotive Manufacturing and Technology,

London (2003)2, pp. 68-71.

SIMON, A.; SCHILLER, E.F.; HACKER, W.:

(Digitale) Unterstützung komplexer Tätigkeiten in der Produktionsplanung:

Anforderungen und erste Ergebnisse.

In: Arbeit + Gesundheit in effizienten Arbeitssystemen.

Ed.: Gesellschaft für Arbeitswissenschaft.

Dortmund: GfA Press, 2004, pp. 291-294.

(Jahresdokumentation 2004) 